\title{
Influência da aplicação de dois resíduos industriais nas propriedades químicas de dois solos cultivados com café arábica ${ }^{1}$
}

\author{
Influence of the application of two types of industrial waste on the chemical \\ properties of soil planted with coffea Arabica
}

\author{
Natiélia Oliveira Nogueira ${ }^{2 *}$, Marcelo Antonio Tomaz ${ }^{3}$, Felipe Vaz Andrade ${ }^{3}$, Edvaldo Fialho dos Reis $^{4}$ e \\ Sebastião Vinícius Batista Brinate ${ }^{5}$
}

\begin{abstract}
Resumo - A grande quantidade de resíduos industriais que constituiu atualmente sérios problemas ambientais tem alertado para a utilização adequada desses materiais que, além de reduzir os impactos ambientais, tem demonstrado potencial para utilização na agricultura. O objetivo deste estudo foi avaliar os efeitos químicos da aplicação de diferentes doses de escória de siderurgia e óxido de magnésio em dois solos sob o cultivo de café arábica. O estudo foi desenvolvido em casa de vegetação do Centro de Ciências Agrárias da Universidade Federal do Espírito Santo, em vasos de $10 \mathrm{dm}^{3}$. O delineamento experimental foi instalado em blocos casualizados, com distribuição fatorial de $2 \times 3 \times 6$, com três repetições, sendo os fatores: dois solos (Latossolo Vermelho-Amarelo distrófico de textura argilosa e Latossolo Vermelho-Amarelo distrófico de textura média); três insumos (calcário como controle e escória de siderurgia e óxido de magnésio como resíduos); seis doses dos materiais corretivos ( 0 ; 25; $50 ; 75 ; 100$ e $125 \%$ da necessidade de calagem). Após 180 dias de cultivo, procedeu-se as análises de $\mathrm{pH}, \mathrm{H}^{+}+\mathrm{Al}^{3+}, \mathrm{Al}^{3+}, \mathrm{Ca}^{2+}$ e $\mathrm{Mg}^{2+}$. Os resultados mostraram que as aplicações de doses crescentes de escória e óxido de magnésio até o limite estudado neste trabalho favorecem um decréscimo da acidez do solo. O óxido de magnésio demonstrou maior potencial como corretivo de acidez de solo e como fonte de magnésio para o solo.
\end{abstract}

Palavras-chave - Acidez do solo. Fertilidade do solo. Resíduos.

\begin{abstract}
The large amount of industrial waste which currently causes serious environmental problems has demonstrated the need for the appropriate use of those materials which not only reduce environmental impact but have shown potential for agricultural use. The aim of this study was to evaluate the chemical effects of different amounts of slag and magnesium oxide on two soils planted with coffea arabica. The study was carried out using pots of $10 \mathrm{dm}^{3}$ in a greenhouse at the Center for Agrarian Sciences of the Federal University of Espirito Santo. The experimental design was of randomized blocks with a factorial distribution of $2 \times 3 \times 6$, and three replications, the factors being: two soils (dystrophic red-yellow clay loam and dystrophic red-yellow medium-texture loam), three additives (limestone as control and slag and magnesium oxide as waste), six amounts of corrective materials $(0 ; 25 ; 50 ; 75 ; 100$ and $125 \%$ of the required liming). After 180 days of culture, analysis of $\mathrm{pH}, \mathrm{H}^{+}+\mathrm{Al}^{3+}, \mathrm{Al}^{3+}, \mathrm{Ca}^{2+} \mathrm{e} \mathrm{Mg}^{2+}$ was carried out. The results showed that applications of increasing doses of magnesium oxide and slag, up to the limit of this study, further a decrease in soil acidity. Magnesium oxide has shown the greatest potential for soil-acidity correction and also as a source of magnesium for the soil.
\end{abstract}

Key words - Soil acidity. Soil fertility. Residues.

\footnotetext{
* Autor para correspondência

${ }^{1}$ Recebido para publicação em 23/05/2010; aprovado em 14/06/2011

Parte da Dissertação de Mestrado da primeira autora apresentada no Programa de Pós-Graduação em Produção Vegetal da Universidade Federal do Espírito Santo

${ }^{2}$ Programa de Pós-Graduação em Produção Vegetal, Universidade Federal do Espírito Santo/CCA/UFES, Alegre-ES, Brasil, 29.500-000, natielia_nogueira@yahoo.com.br

${ }^{3}$ Departamento de Produção Vegetal, Universidade Federal do Espírito Santo/CCA/UFES, Alegre-ES, Brasil, 29.500-000, tomazamarcelo@ yahoo.com.br, felipevazandrade@gmail.com

${ }^{4}$ Departamento de Engenharia Rural, Universidade Federal do Espírito Santo/CCA/UFES, Alegre-ES, Brasil, 29.500-000, edreis@cca.ufes.br

${ }^{5}$ Graduando em Agronomia da Universidade Federal do Espírito Santo/CCA/UFES, Alegre-ES, Brasil, 29.500-000, svbbrinate@hotmail.com
} 


\section{Introdução}

O Brasil se destaca como o maior produtor e o segundo maior consumidor de café do mundo. O Estado do Espírito Santo é o segundo maior produtor de café do país, atrás apenas de Minas Gerais (CONAB, 2009). Um dos fatores que não permite aumentar a capacidade produtiva dos cafezais é o modo de condução das lavouras. Geralmente, as lavouras são conduzidas sem tecnificação, sem manejo adequado do solo e sem a utilização racional de adubos e corretivos de acidez do solo (MORELI, 2010).

Os produtos mais utilizados para neutralizar a acidez do solo são os carbonatos de cálcio $\left(\mathrm{CaCO}_{3}-\right.$ calcita) e de magnésio ( $\mathrm{MgCO}_{3}$ - dolomita), conhecidos comercialmente como calcário dolomítico (NOLLA; ANGHINONI, 2004). Apesar de o calcário ser hoje uma fonte barata e acessível, sua escassez em médio e longo prazo, pode torná-lo caro e de difícil acesso ao produtor rural.

Por outro lado, a grande quantidade de resíduos industriais disponíveis gera problemas ambientais que podem ser resolvidos por meio da reutilização na agricultura. $\mathrm{O}$ emprego da escória de siderurgia e óxido de magnésio na agricultura como corretivos de acidez do solo, surge como uma alternativa ao calcário, objetivando corrigir a acidez do solo e reduzir possíveis impactos ao ambiente.

Entre os resíduos industriais, destaca-se a escória de siderurgia, que é constituída por silicatos de cálcio $\left(\mathrm{Ca}_{2} \mathrm{SiO}_{3}\right)$ e de magnésio $\left(\mathrm{Mg}_{2} \mathrm{SiO}_{3}\right)$, e comporta-se de maneira semelhante aos calcários (PRADO; FERNANDES, 2000a). No Brasil, vem crescendo significativamente nos últimos anos o interesse por pesquisas que tratam da utilização de escórias (FORTES et al., 2008). Nesse sentido, o emprego de escórias industriais na agricultura tem sido estudado por alguns autores, que têm confirmado a sua viabilidade para diferentes culturas, como Paparotte e Maciel (2006), Prado e Natale (2004), Oliveira et al. (2010), Stocco et al. (2010).

Outro material industrial que apresenta potencial de utilização na cultura do café, como fonte de $\mathrm{Mg}^{2+}$ e correção de acidez do solo, é o óxido de magnésio $(\mathrm{MgO})$, obtido da calcinação da Magnesita $\left(\mathrm{MgCO}_{3}\right)$. Esse óxido é um produto intermediário do processo industrial de produção de refratários.

O objetivo deste estudo foi avaliar os efeitos químicos da aplicação de diferentes doses de escória de siderurgia e óxido de magnésio em dois solos sob cultivo de café arábica.

\section{Material e métodos}

O experimento foi conduzido em casa de vegetação do Centro de Ciências Agrárias da Universidade Federal do Espírito Santo em Alegre - ES. O local situa-se a uma altitude aproximada de $250 \mathrm{~m}$, com coordenadas

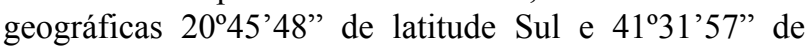
longitude Oeste. O clima predominante na região é do tipo Cwa (clima subtropical, quente e úmido no verão e seco no inverno), conforme classificação de Köppen, com precipitação anual média de $1.200 \mathrm{~mm}$ e temperatura média anual de $23{ }^{\circ} \mathrm{C}$.

Para a realização deste experimento, foram coletadas amostras superficiais de um Latossolo Vermelho-Amarelo distrófico de textura argilosa (LVAarg), e um Latossolo Vermelho-Amarelo distrófico de textura média (LVAmed), no município de Alegre-ES (EMBRAPA, 2006). O solo foi seco ao ar, destorroado e passado em peneira de 2,0 $\mathrm{mm}$ para obtenção da terra fina seca ao ar (TFSA) e realizado sua caracterização física e química (TAB. 1).

Tabela 1 - Atributos físicos e químicos dos solos estudados

\begin{tabular}{|c|c|c|}
\hline Atributos & LVAarg & LVAmed \\
\hline${ }^{1}$ Areia $\left(\mathrm{g} \mathrm{kg}^{-1}\right)$ & 474,8 & 615,8 \\
\hline${ }^{1}$ Silte $\left(\mathrm{g} \mathrm{kg}^{-1}\right)$ & 63,6 & 35,1 \\
\hline${ }^{1}$ Argila $\left(\mathrm{g} \mathrm{kg}^{-1}\right)$ & 461,6 & 349,1 \\
\hline${ }^{2}$ Densidade do solo $\left(\mathrm{kg} \mathrm{dm}^{-3}\right)$ & 1,20 & 1,05 \\
\hline${ }^{3} \mathrm{pH}$ & 4,0 & 4,2 \\
\hline${ }^{4} \mathrm{Ca}^{2+}\left(\mathrm{cmol}_{\mathrm{c}} \mathrm{dm}^{-3}\right)$ & 0,7 & 2,0 \\
\hline${ }^{4} \mathrm{Mg}^{2+}\left(\mathrm{cmol}_{\mathrm{c}} \mathrm{dm}^{-3}\right)$ & 0,4 & 0,4 \\
\hline${ }^{5} \mathrm{Al}^{3+}\left(\mathrm{cmol}_{\mathrm{c}} \mathrm{dm}^{-3}\right)$ & 0,9 & 0,6 \\
\hline${ }^{6} \mathrm{H}^{+}+\mathrm{Al}^{3+}\left(\mathrm{cmol}_{\mathrm{c}} \mathrm{dm}^{-3}\right)$ & 8,5 & 3,5 \\
\hline${ }^{7}$ Matéria orgânica $\left(\mathrm{g} \mathrm{kg}^{-3}\right)$ & 31,4 & 13,3 \\
\hline Soma de Bases $\left(\mathrm{cmol}_{\mathrm{c}} \mathrm{dm}^{-3}\right)$ & 1,2 & 2,5 \\
\hline CTC potencial $\left(\mathrm{cmol}_{\mathrm{c}} \mathrm{dm}^{-3}\right)$ & 9,7 & 6,0 \\
\hline Saturação por bases (\%) & 12,0 & 41,8 \\
\hline
\end{tabular}

${ }^{1}$ Método da Pipeta (Agitação Lenta); ${ }^{2}$ Método da Proveta; ${ }^{3 .} \mathrm{pH}$ em água (relação 1:2,5); ${ }^{4}$ Extraído com cloreto de potássio $1 \mathrm{~mol} \mathrm{~L}^{-1} \mathrm{e}$ determinado por espectrofotômetro de absorção atômica; ${ }^{5}$ Extraído com cloreto de potássio $1 \mathrm{~mol} \mathrm{~L}^{-1}$ e determinado por titulometria; ${ }^{6}$ Extraído com acetato de cálcio $0,5 \mathrm{~mol} \mathrm{~L}^{-1}, \mathrm{pH} \mathrm{7,0}$ e determinado por titulação; 7. Extraído por oxidação, via úmida, com dicromato de potássio em meio sulfúrico e determinado por titulação (EMBRAPA, 1997)

O delineamento experimental utilizado foi em blocos casualizados (DBC), com distribuição fatorial de $2 \times 3 \times 6$, com três repetições, sendo os fatores: dois 
solos (LVAarg e LVAmed), três insumos, (calcário como controle e escória de siderurgia e óxido de magnésio como resíduos) e seis doses dos materiais corretivos $(0 ; 25 ; 50$; $75 ; 100$ e $125 \%$ da necessidade de calagem). As doses foram definidas utilizando-se o método da elevação da saturação de bases, com a elevação da saturação de bases para $60 \%$, conforme sugerido por Prezotti et al. (2007).

As amostras de materiais corretivos utilizadas foram padronizadas através de passagem em peneira de 60 Mesh $(250 \mu \mathrm{m})$, e secas em estufa a $105^{\circ} \mathrm{C}$. Subamostras foram utilizadas para análises químicas (TAB. 2).

Tabela 2 - Características químicas dos corretivos utilizados

\begin{tabular}{lrrc}
\hline \multicolumn{1}{c}{ Parâmetro } & CAL & ESC & OXM \\
\hline Óxido de cálcio (\%) & 31,4 & 37,0 & - \\
Óxido de magnésio (\%) & 10,6 & 12,6 & 53,0 \\
Dióxido de silício (\%) & - & 21,3 & - \\
'Poder de neutralização & 82,5 & 97,5 & 195,0 \\
${ }^{2}$ Eficiência Relativa (\%) & 100,0 & 100,0 & 100,0 \\
${ }^{3}$ PRNT (\%) & 82,5 & 97,5 & 195,0 \\
\hline
\end{tabular}

${ }^{1}$ Poder de neutralização: $\% \mathrm{CaO}$ x $1,79+\% \mathrm{MgO}$ x2,48; ${ }^{2}$ Eficiência relativa: $[(\mathrm{A} \times 0,0)+(\mathrm{B} \times 0,2)+(\mathrm{C} \times 0,6)+(\mathrm{D} \times 1,0) / 100]$, sendo $\mathrm{A}$, $\mathrm{B}, \mathrm{C}=\%$ de corretivo que fica retido, respectivamente, nas peneiras $\mathrm{n}^{\circ} 10,20$ e 50 , e $\mathrm{D}=\%$ de corretivo que passa na peneira $\mathrm{n}^{\circ} 50$; ${ }^{3}$ PRNT $=$ PN $x$ ER $/ 100$

Após as análises dos solos, eles foram separados em amostras de $10 \mathrm{dm}^{3}$ e submetidos à aplicação dos tratamentos (aplicação das fontes e doses de materiais corretivos). Em seguida as amostras de solos foram acondicionadas em sacos plásticos e incubadas por 28 dias, mantendo-se a umidade do solo a $60 \%$ do volume total de poros (VTP), de acordo com Freire et al. (1980). Foram realizadas pesagens diárias para reposição das perdas de água do solo.

As amostras, após o período de incubação, foram secas à sombra e homogeneizadas em peneira de malha $2 \mathrm{~mm}$, para realização da adubação com fósforo e potássio, de acordo com Prezotti et al. (2007). Para os tratamentos com óxido de magnésio, utilizou-se $\mathrm{KH}_{2} \mathrm{PO}_{4}$ como fonte de potássio e fósforo e para os tratamentos com calcário e escória utilizou-se o $\mathrm{KCl}$ como fonte de potássio e $\mathrm{CaHPO}_{4}, \mathrm{CaSO}_{4}$ como fonte de cálcio e fosfato. Com o objetivo de se igualar a relação $\mathrm{Ca}^{2+}$ e $\mathrm{Mg}^{2+}$ entre os corretivos em 3:1, essa relação é ideal para a nutrição do cafeeiro e propicia um melhor desenvolvimento das plantas.
Em seguida, as amostras de solos foram colocadas em vasos plásticos com capacidade para $15 \mathrm{dm}^{3}$ e efetuou-se o plantio das mudas de café da cultivar Catuaí 44, que apresentavam três pares de folhas. A irrigação foi realizada diariamente com água destilada, mantendo-se a umidade constante para todos os vasos por meio de pesagens.

A adubação nitrogenada com sulfato de amônio P.A foi realizada em cobertura, baseando-se na marcha de acúmulo de nutrientes conforme Malavolta (1984). As doses (20 mg de nitrogênio por vaso) foram divididas em cinco aplicações aos 30; 60; 90; 120 e 150 dias após o plantio. Após 180 dias de cultivo, foram retiradas subamostras de solos das unidades experimentais

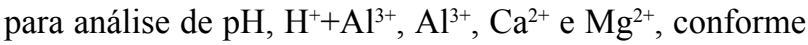
EMBRAPA (1997).

Os dados foram submetidos aos testes preliminares para verificação da normalidade e homogeneidade de variância dos mesmos, aos testes de Lilliefors e teste de Bartlett, respectivamente. Posteriormente, os dados foram submetidos à análise de variância $(p \leq 0,05)$, utilizando-se o Software SISVAR (FERREIRA, 2000). Quando significativos foi utilizado o teste de Tukey ( $\mathrm{p} \leq 0,01)$ para os fatores qualitativos e a análise de regressão para os fatores quantitativos. Os modelos foram escolhidos com base na significância dos coeficientes de regressão, utilizando-se o teste t de Student ao nível de 5\% de probabilidade e pelo coeficiente de determinação $\left(\mathrm{R}^{2}\right)$.

\section{Resultados e discussão}

Na Tabela 3 estão apresentados os resultados da análise de variância para as variáveis analisadas. Verificandose o valor de $\mathrm{pH}$ para os solos estudados, pode ser observado que houve diferença significativa entre os Latossolos quando utilizados todos os corretivos, sendo que o LVAarg apresentou maiores valores da variável analisada (TAB. 4).

Verifica-se para o LVAarg que foram encontrados maiores valores de $\mathrm{pH}$ do solo quando utilizado o óxido de magnésio, que diferiu dos demais corretivos estudados. No entanto, para o LVAmed notou-se que não houve diferença estatística entre os corretivos.

Os corretivos à base de silicatos têm mostrado efeitos positivos na correção da acidez do solo e no aumento da disponibilidade de cálcio (BARBOSA FILHO et al., 2001). Resultados semelhantes ao encontrado neste estudo foram obtidos por Prado e Fernandes (2001), que utilizou escória de siderurgia e calcário como corretivos da acidez do solo no préplantio de cana-de-açúcar e não observaram diferenças entre ambos. 
Mesquita et al. (2008) estudando a escória de siderurgia e óxido de magnésio como corretivos da acidez em Latossolos, verificaram que o óxido de magnésio apresentou comportamento semelhante ao calcário na elevação do $\mathrm{pH}$ dos solos estudados.

$\mathrm{O}$ aumento do $\mathrm{pH}$ em solos ácido é essencial para uma boa produtividade das culturas. $\mathrm{O} \mathrm{pH}$ do solo influencia, de forma indireta, o desenvolvimento das culturas, evidenciado por meio das mudanças que provoca na solubilidade dos elementos essenciais e tóxicos existentes no solo, alterando a disponibilidades dos mesmos (VITTI, 1987 apud CHAVES et al., 2006). Segundo Sousa et al. (2007) a redução da acidez do solo promove a insolubilização de alumínio e manganês, aumenta a disponibilidade de fósforo e molibdênio e diminui a disponibilidade de micronutrientes, como o zinco, manganês, cobre e ferro. A decomposição da matéria orgânica também é influenciada pela redução da acidez do solo, sendo sua mineralização favorecida pela elevação do $\mathrm{pH}$ do solo.
Observa-se na Figura 1 que há aumentos dos valores de $\mathrm{pH}$ do solo à medida que se incrementavam as doses de corretivos para os dois Latossolos. Verifica-se por meio de modelos ajustados para os valores de $\mathrm{pH}$ do solo, em função das doses dos corretivos estudados, um ajuste linear para o LVAarg (FIG. 1a). Para o LVAmed observou-se respostas lineares do $\mathrm{pH}$ do solo quando utilizadas as doses do corretivo escória e respostas quadráticas quando foi aplicado o calcário e óxido de magnésio (FIG. 1b). No entanto, com exceção das maiores doses dos corretivos para o LVAarg, os valores de $\mathrm{pH}$ dos demais corretivos para os solos estudados, ainda se encontram dentro da faixa de acidez elevada. Segundo Sousa et al. (2007), valores de pH em água, abaixo de 5,1 são considerados solos de elevada acidez.

Este fato pode ter ocorrido em função do LVAmed ser um solo de textura média e apresentar menor fator capacidade tampão para $\mathrm{pH}$, pode ter sofrido variação de $\mathrm{pH}$ mais rapidamente no decorrer dos 180 dias do

Tabela 3 - Valores dos quadrados médios e coeficientes de variação (CV) dos valores de $\mathrm{pH}, \mathrm{H}^{+}+\mathrm{Al}^{3+}, \mathrm{Al}^{3+}$, cálcio e magnésio do solo em função das doses $(0 ; 25 ; 50 ; 75 ; 100$ e 125\% da necessidade de corretivo) dos corretivos (calcário, escória e óxido de magnésio) para o Latossolo Vermelho-Amarelo de textura argilosa (LVAarg) e para o Latossolo Vermelho-Amarelo de textura média (LVAmed)

\begin{tabular}{lcrrrrc}
\hline \multirow{2}{*}{ Fontes de variação } & \multirow{2}{*}{$\mathrm{GL}$} & \multicolumn{5}{c}{ Quadrados Médios } \\
\cline { 3 - 6 } & & $\mathrm{pH}$ & $\mathrm{H}^{+}+\mathrm{Al}^{3+}$ & $\mathrm{Al}^{3+}$ & $\mathrm{Ca}^{2+}$ & $\mathrm{Mg}^{2+}$ \\
\hline Bloco & 2 & $0,212^{* *}$ & $0,175^{\text {ns }}$ & $0,016^{\text {ns }}$ & $0,131^{\text {ns }}$ & $0,003^{\text {ns }}$ \\
Solo & 1 & $11,278^{* *}$ & $130,020^{* *}$ & $1,638^{* *}$ & $48,951^{* *}$ & $9,588^{* *}$ \\
Corretivo & 2 & $0,521^{* *}$ & $12,504^{* *}$ & $0,782^{* *}$ & $10,024^{* *}$ & $5,029^{* *}$ \\
Dose & 5 & $1,103^{* *}$ & $17,416^{* *}$ & $3,057^{* *}$ & $16,340^{* *}$ & $2,404^{* *}$ \\
Solo x corretivo & 2 & $0,073^{\text {ns }}$ & $0,827^{* *}$ & $0,661^{* *}$ & $2,727^{* *}$ & $1,000^{* *}$ \\
Solo x dose & 5 & $0,347^{* *}$ & $6,996^{* *}$ & $0,117^{* *}$ & $1,088^{* *}$ & $0,701^{* *}$ \\
Corretivo x dose & 10 & $0,055^{\text {ns }}$ & $1,327^{* *}$ & $0,118^{* *}$ & $0,555^{* *}$ & $0,465^{* *}$ \\
Solo x corretivo x dose & 10 & $0,041^{\text {ns }}$ & $0,421^{* *}$ & $0,032^{\text {ns }}$ & $0,457^{* *}$ & $0,175^{* *}$ \\
CV\% & & 4,260 & 7,430 & 25,230 & 7,700 & 5,220 \\
\hline
\end{tabular}

** Significativo a $1 \%$; $\mathrm{e}^{\text {ns }}$ não significativo pelo teste $\mathrm{F}$

Tabela 4 - Valores médios de pH do solo, em função do tipo de corretivo (calcário, escória e óxido de magnésio) para o Latossolo Vermelho-Amarelo de textura argilosa (LVAarg) e Latossolo Vermelho-Amarelo de textura média (LVAmed)

\begin{tabular}{ccc}
\hline \multirow{2}{*}{ Corretivos } & \multicolumn{2}{c}{$\mathrm{pH}$} \\
\cline { 2 - 3 } & LVAarg & LVAmed \\
\hline CAL & $4,64 \mathrm{bB}$ & $4,09 \mathrm{aA}$ \\
ESC & $4,76 \mathrm{bB}$ & $4,08 \mathrm{aA}$ \\
OXM & $4,96 \mathrm{aB}$ & $4,24 \mathrm{aA}$ \\
\hline
\end{tabular}

*Médias seguidas de mesma letra, maiúscula nas linhas e minúscula nas colunas, não diferem significativamente entre si pelo teste de Tukey $(\mathrm{p}<0,05)$ 


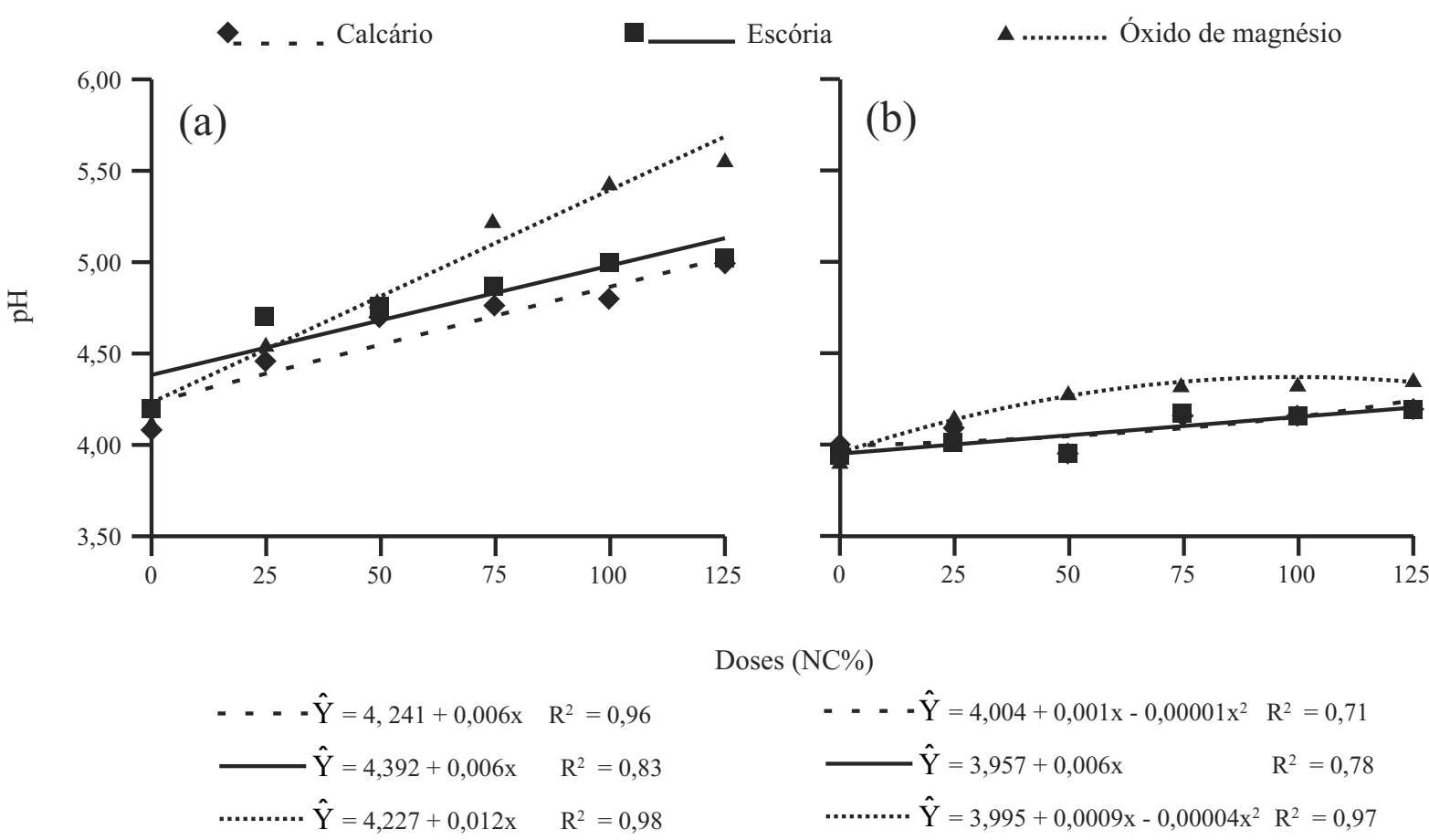

Figura 1 - Valores médios de $\mathrm{pH}$ do solo para cada tipo de corretivo (calcário, escória e óxido de magnésio) em função das doses $(0 ; 25 ; 50 ; 75 ; 100$ e $125 \%$ da necessidade de corretivo) estudadas para o Latossolo Vermelho-Amarelo de textura argilosa (LVAarg) (a) e Latossolo Vermelho-Amarelo de textura média (LVAmed) (b)

experimento, tanto pela retirada de cátions pelas plantas, como também pela influência de adubações com sulfato de amônio em cobertura. Fato semelhante foi discutido por Prado e Fernandes (2000b).

O fator capacidade tampão será tanto maior quanto mais elevado o teor de argilominerais, óxidos e de matéria orgânica (grupos $\mathrm{COOH}$ ), que são fontes de $\mathrm{H}^{+}$e $\mathrm{Al}^{3+}$ para solução do solo (MORELLI, 1986). Assim, solos menos argilosos e/ou pobres em matéria orgânica como o LVAmed (34,9\% de argila e $13,3 \mathrm{~g} \mathrm{~kg}^{-1}$ de matéria orgânica) têm, portanto, menor fator capacidade tampão, em relação ao LVAarg com 46,16\% de argila e $31,40 \mathrm{~g} \mathrm{~kg}^{-1}$ de matéria orgânica (TAB. 1).

Quando se avalia o comportamento dos corretivos utilizados em relação aos valores de acidez potencial ou total $\left(\mathrm{H}^{+}+\mathrm{Al}^{3+}\right)$ no solo, verifica-se na Tabela 5, que para o LVAarg, houve diferença significativa entre os corretivos, apresentando valores inferiores da variável estudada quando aplicado o óxido de magnésio, seguidos dos corretivos calcário e escória. Os valores de $\mathrm{H}^{+}+\mathrm{Al}^{3+}$ obtidos no solo LVAmed, após a correção, foram menores com a utilização do óxido de magnésio quando comparado aos demais. Possivelmente, a diferenciação do óxido de magnésio dos demais corretivos pode estar associada à alta solubilidade desse corretivo, o óxido de magnésio possui cerca de duas vezes mais o poder de neutralização comparada ao calcário padrão.

Analisando a Tabela 5, para os dois solos utilizados, observou-se diferença significativa entre os valores médios de $\mathrm{H}^{+}+\mathrm{Al}^{3+}$ para o LVAarg e LVAmed. Os maiores valores observados para o LVAarg podem estar relacionados ao elevado valor de $\mathrm{H}^{+}+\mathrm{Al}^{3+}$ no solo antes da aplicação das doses dos corretivos, conforme observado na Figura 2a. Os elevados valores para a dose zero, neste solo contribuíram para maiores valores médios para esta variável.

Por meio do estudo do modelo, verifica-se que há diminuição da acidez potencial para os dois solos estudados (FIG. 2). No LVAarg, observa-se ajuste quadrático dos teores de $\mathrm{H}^{+}+\mathrm{Al}^{3+}$ quando utilizados os corretivos calcário e óxido de magnésio e redução linear quando utilizada a escória (FIG. 2a). Enquanto que para o LVAmed, observa-se redução linear do $\mathrm{H}^{+}+\mathrm{Al}^{3+}$, quando utilizados os corretivos escória e óxido de magnésio. Para o calcário não foi possível ajustar um modelo de regressão (FIG. 2b).

A acidez potencial do solo $\left(\mathrm{H}^{+}+\mathrm{Al}^{3+}\right)$ diminuiu com a adição dos corretivos, quando comparado à testemunha. A maior redução ocorreu nos tratamentos com maiores 
Tabela 5 - Valores médios de $\mathrm{H}^{+}+\mathrm{Al}^{3+}\left(\mathrm{cmol}_{\mathrm{c}} \mathrm{dm}^{-3}\right)$ do solo em função do tipo de corretivo (calcário, escória e óxido de magnésio) para o Latossolo Vermelho-Amarelo de textura argilosa (LVAarg) e Latossolo Vermelho-Amarelo de textura média (LVAmed)

\begin{tabular}{clc}
\hline \multirow{2}{*}{ Corretivos } & \multicolumn{2}{c}{$\mathrm{H}^{+}+\mathrm{Al}^{3+}\left(\mathrm{cmol}_{\mathrm{c}} \mathrm{dm}^{-3}\right)$} \\
\cline { 2 - 3 } & LVAarg & LVAmed \\
\hline CAL & $6,68 \mathrm{bA}$ & $4,66 \mathrm{aB}$ \\
ESC & $7,03 \mathrm{aA}$ & $4,48 \mathrm{aB}$ \\
OXM & $5,71 \mathrm{cA}$ & $3,68 \mathrm{bB}$ \\
\hline
\end{tabular}

*Médias seguidas de mesma letra, maiúscula nas linhas e minúscula nas colunas, não diferem significativamente entre si pelo teste de Tukey $(\mathrm{p}<0,05)$

doses de corretivos, que apresentaram valores de $\mathrm{pH}$ significativamente superiores aos demais (FIG. 1).

A maioria dos valores médios de $\mathrm{H}^{+}+\mathrm{Al}^{3+}$ encontrados para o LVAarg estão dentro da faixa considerada por Prezotti et al. (2007) de alta acidez (valores maiores que $5,0 \mathrm{cmol}_{\mathrm{c}} \mathrm{dm}^{-3}$ ), com valores menores quando aplicadas as doses $75 ; 100$ e $125 \%$ da necessidade de corretivo. Estes valores elevados ao final do experimento podem estar relacionados ao alto valor de $\mathrm{H}^{+}+\mathrm{Al}^{3+}$ no solo antes da aplicação dos corretivos, conforme observado na Figura 2. Enquanto que todos os valores encontrados para o LVAmed se enquadram dentro da faixa de média acidez para Prezotti et al. (2007) $\left(2,5\right.$ a 5,0 $\left.\mathrm{cmol}_{\mathrm{c}} \mathrm{dm}^{-3}\right)$ (FIG. 2b).

Para acidez trocável, ou teor de alumínio $\left(\mathrm{Al}^{3+}\right)$ no solo, verifica-se na Tabela 6, que os dois Latossolos não diferiram estatisticamente entre si, quando utilizado a escória. No entanto, para o LVAarg quando aplicado o calcário e o óxido de magnésio, observa-se menores valores de $\mathrm{Al}^{3+}$, ocorrendo nestas condições, uma maior correção de acidez neste solo.

Verifica-se para o LVAarg, uma maior redução dos valores obtidos de $\mathrm{Al}^{3+}$ com a aplicação do óxido de magnésio, que por sua vez não diferiu estatisticamente do calcário. Não se observa diferença entre calcário e escória, e também entre os corretivos calcário e óxido de magnésio. No LVAmed, a escória não diferiu do óxido de magnésio, mas ambos diferiram do calcário (TAB. 6). Este fato pode estar relacionado à maior reatividade do óxido de magnésio comparado aos demais estudados.

Os resultados dos corretivos alternativos (escória e óxido de magnésio) na correção da acidez do solo evidenciam os efeitos positivos na redução dos fatores

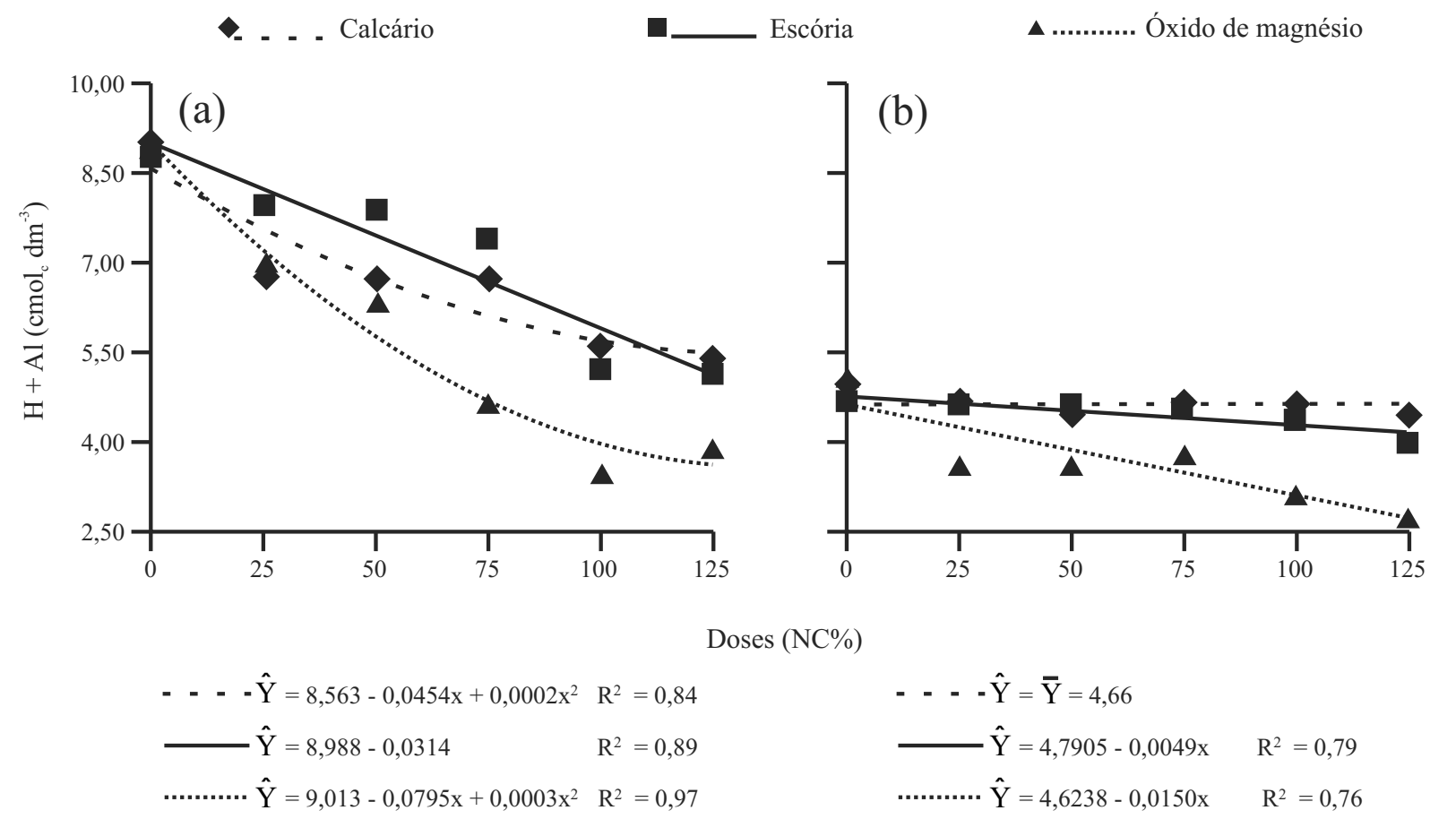

Figura 2 - Valores médios de $\mathrm{H}^{+}+\mathrm{Al}^{3+}\left(\mathrm{cmol}_{\mathrm{c}} \mathrm{dm}^{-3}\right)$ do solo para cada tipo de corretivo (calcário, escória e óxido de magnésio) em função das doses estudadas $(0,25,50,75,100$ e 125\% da necessidade de corretivo) para o LVAarg) (a) e o LVAmed (b) 
Tabela 6 - Valores médios de $\mathrm{Al}^{3+}\left(\mathrm{cmol}_{\mathrm{c}} \mathrm{dm}^{-3}\right)$ do solo em função do tipo de corretivo (calcário, escória e óxido de magnésio) para o Latossolo Vermelho-Amarelo de textura argilosa (LVAarg) e Latossolo Vermelho-Amarelo de textura média (LVAmed)

\begin{tabular}{clc}
\hline \multirow{2}{*}{ Corretivos } & \multicolumn{2}{c}{$\mathrm{Al}^{3+}\left(\mathrm{cmol}_{\mathrm{c}} \mathrm{dm}^{-3}\right)$} \\
\cline { 2 - 3 } & LVAarg & LVAmed \\
\hline CAL & $0,48 \mathrm{abB}$ & $1,03 \mathrm{aA}$ \\
ESC & $0,57 \mathrm{aA}$ & $0,62 \mathrm{bA}$ \\
OXM & $0,39 \mathrm{bB}$ & $0,53 \mathrm{bA}$ \\
\hline
\end{tabular}

*Médias seguidas de mesma letra, maiúscula nas linhas e minúscula nas colunas, não diferem significativamente entre si pelo teste de Tukey $(\mathrm{p}<0,05)$

indicadores de acidez. Resultados semelhantes foram obtidos por Prado e Fernandes (2000b) em um Latossolo Vermelho distrófico e de um Neossolo Quartzarênico, cultivados com cana-de-açúcar em vaso, e por Prado e Fernandes (2001), estudando diferentes níveis de saturação por bases, utilizando como corretivo a escória de siderurgia e o calcário.

Observa-se na Figura $3 a$ e Figura 3b, que o comportamento dos dois Latossolos se ajusta a um modelo de regressão quadrático para os teores de $\mathrm{Al}^{3+}$, com exceção do calcário para o LVAmed que apresentou ajuste linear para tal variável. O óxido de magnésio e a escória de siderurgia demonstram alto potencial de neutralização da acidez do solo com as mesmas doses utilizadas para o calcário, apresentando potencialidade na correção da acidez dos solos.

Os valores médios de $\mathrm{Al}^{3+}$ se enquadram na faixa de acidez elevada apenas para as testemunhas (valores maiores que $1,0 \mathrm{cmol}_{\mathrm{c}} \mathrm{dm}^{-3}$ ) para os dois Latossolos, os demais valores se encontram dentro da faixa considerada por Prezotti et al. (2007), de média acidez no solo (0,3 a $\left.1,0 \mathrm{cmol}_{\mathrm{c}} \mathrm{dm}^{-3}\right)$.

Os valores de cálcio para os dois Latossolos estudados são apresentados na Tabela 7. Observa-se maiores valores de cálcio para o LVAarg frente ao LVAmed, para todos os corretivos avaliados. O fato dos maiores valores de cálcio serem encontrados para o LVAarg, possivelmente está em função do maior teor de matéria orgânica deste solo (TAB. 1), que acarreta maior efeito tampão, que se refere à resistência que tem o solo para variar a quantidade de uma determinada característica. Ao analisar a aplicação dos corretivos, para os dois Latossolos estudados, em relação ao teor de cálcio, verifica-se na Tabela 7, que para o LVAarg, os maiores valores de cálcio são encontrados quando utilizado o óxido de magnésio, seguidos da escória e

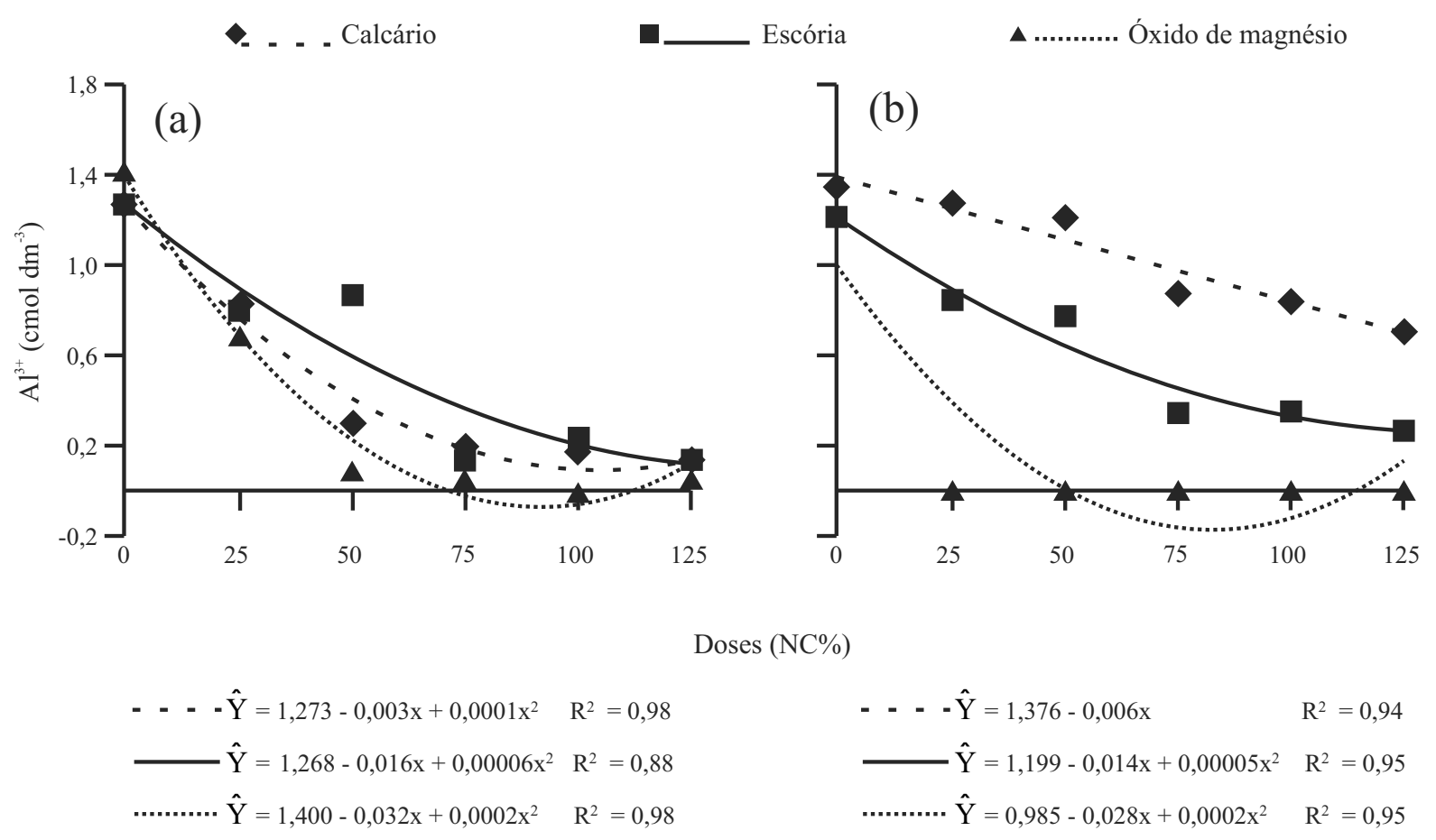

Figura 3 - Valores médios de $\mathrm{Al}^{3+}\left(\mathrm{cmol}_{\mathrm{c}} \mathrm{dm}^{-3}\right)$ do solo para cada tipo de corretivo (calcário, escória e óxido de magnésio) em função das doses estudadas $(0,25,50,75,100$ e $125 \%$ da necessidade de corretivo) para o LVAarg) (a) e o LVAmed (b) 
calcário. Para o LVAmed, os maiores valores de cálcio são observados para o óxido de magnésio, seguido de calcário e escória.

Os maiores valores de cálcio no solo proporcionados pela aplicação do óxido de magnésio observado em todos os tratamentos com este corretivo, está em função da

Tabela 7 - Valores médios de cálcio $\left(\mathrm{cmol}_{\mathrm{c}} \mathrm{dm}^{-3}\right)$ do solo em função do tipo de corretivo (calcário, escória e óxido de magnésio) para o Latossolo Vermelho-Amarelo de textura argilosa (LVAarg) e Latossolo Vermelho-Amarelo de textura média (LVAmed)

\begin{tabular}{clc}
\hline \multirow{2}{*}{ Corretivos } & \multicolumn{2}{c}{ Cálcio $\left(\mathrm{cmol}_{\mathrm{c}} \mathrm{dm}^{-3}\right)$} \\
\cline { 2 - 3 } & LVAarg & LVAmed \\
\hline CAL & $3,34 \mathrm{cA}$ & $2,83 \mathrm{bB}$ \\
ESC & $3,95 \mathrm{bA}$ & $2,41 \mathrm{cB}$ \\
OXM & $4,74 \mathrm{aA}$ & $3,33 \mathrm{aB}$ \\
\hline
\end{tabular}

*Médias seguidas de mesma letra, maiúscula nas linhas e minúscula nas colunas, não diferem não diferem significativamente entre si pelo teste de Tukey $(\mathrm{p}<0,05)$ aplicação conjunta com o $\mathrm{CaSO}_{4}$ utilizado para balancear a relação de cálcio e magnésio do corretivo.

O comportamento e a eficiência dos corretivos no solo dependem de suas características, como a natureza química dos neutralizantes, o poder de neutralização, a solubilidade e a granulometria.

Os teores de cálcio no solo apresentam incrementos lineares à medida que se aumentava as doses de todos os corretivos aplicados para o LVAarg (FIG. 4a). Para o LVAmed, os modelos de regressão com coeficientes estatisticamente significativos apresentaram, quanto aos teores de cálcio no solo, o comportamento linear para o calcário, quadráticos quando utilizado o óxido de magnésio e, para o corretivo escória, não foi possível obter-se um coeficiente estatisticamente significativo (FIG. 4b).

A maioria dos teores de cálcio no solo encontrados para o LVAarg estão dentro da faixa considerada por Prezotti et al. (2007), de alto valor de cálcio no solo (valores maiores que $4,0 \mathrm{cmol}_{\mathrm{c}} \mathrm{dm}^{-3}$ ), enquanto que todos os valores encontrados para o LVAmed se enquadram dentro da faixa de médio valor de cálcio $\left(1,5 \mathrm{a} 4,0 \mathrm{cmol}_{\mathrm{c}} \mathrm{dm}^{-3}\right) \mathrm{com}$ exceção das testemunhas (FIG. 4). A menor quantidade encontrada deste nutriente no LVAmed pode ser explicado

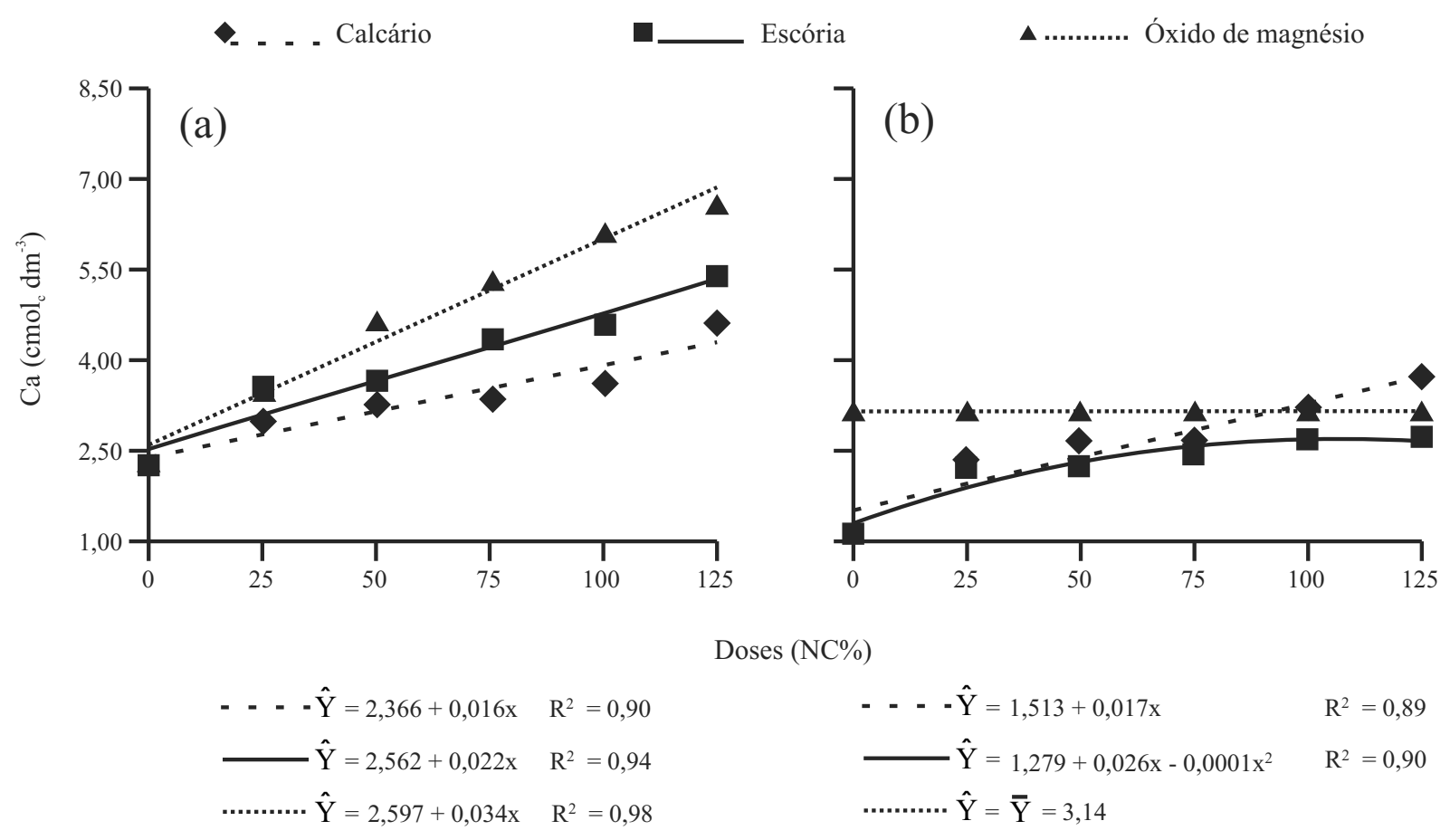

Figura 4 - Valores médios de cálcio $\left(\mathrm{cmol}_{\mathrm{c}} \mathrm{dm}^{-3}\right)$ do solo para cada tipo de corretivo (calcário, escória e óxido de magnésio) em função das doses $(0 ; 25 ; 50 ; 75 ; 100$ e $125 \%$ da necessidade de corretivo) estudadas para o Latossolo Vermelho-Amarelo de textura argilosa (LVAarg) (a) e Latossolo Vermelho-Amarelo de textura média (LVAmed) (b) 
pelo menor poder tampão deste solo, conforme comentado anteriormente.

Analisando o teor de magnésio no solo, observase na Tabela 8 que houve diferença significativa entre os dois Latossolos; os maiores valores foram encontrados para o LVAarg frente ao LVAmed, para todos os corretivos avaliados. Para os valores de magnésio no solo, em função dos corretivos para os dois Latossolos, verifica-se valores superiores para o corretivo óxido de magnésio, seguidos de calcário e escória.

Estes resultados são similares aos encontrados por Vecchi (1993), onde a aplicação de óxido de magnésio em solos cultivados com Citricultura corrigiu a acidez do solo e forneceu teores adequados de magnésio.

Ao analisar os teores de magnésio no solo, verifica-se que há aumentos lineares deste nutriente quando utilizado todos os corretivos testados em relação às doses aplicadas no LVAarg (FIG. 5a) e LVAmed (FIG. 5b).

Os teores de magnésio observados no LVAarg encontram-se abaixo da faixa média $\left(0,5\right.$ a $1,0 \mathrm{cmol}_{\mathrm{c}}$ $\mathrm{dm}^{-3}$ ) preconizado por Prezotti et al. (2007), apenas para as testemunhas. Já para as doses 25, 50 e 75\% tanto para o calcário quanto para a escória, os valores

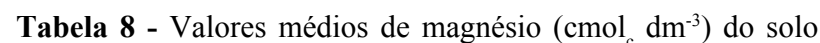
em função do tipo de corretivo (calcário, escória e óxido de magnésio) para o Latossolo Vermelho-Amarelo de textura argilosa (LVAarg) e Latossolo Vermelho-Amarelo de textura média (LVAmed)

\begin{tabular}{ccc}
\hline \multirow{2}{*}{ Corretivos } & \multicolumn{2}{c}{ Magnésio $\left(\mathrm{cmol}_{\mathrm{c}} \mathrm{dm}^{-3}\right)$} \\
\cline { 2 - 3 } & LVAarg & LVAmed \\
\hline CAL & $0,84 \mathrm{bA}$ & $0,45 \mathrm{bB}$ \\
ESC & $0,86 \mathrm{bA}$ & $0,44 \mathrm{bB}$ \\
OXM & $1,78 \mathrm{aA}$ & $0,80 \mathrm{aB}$ \\
\hline
\end{tabular}

*Médias seguidas de mesma letra, maiúscula nas linhas e minúscula nas colunas, não diferem significativamente entre si pelo teste de Tukey $(\mathrm{p}<0,05)$

de magnésio se encontram na faixa média. E os demais tratamentos se encontram acima da faixa média dos valores de magnésio no solo, onde ocorreu maior liberação de magnésio no solo no período estudado (FIG. 5).

Carvalho-Pupatto et al. (2003) verificaram que o aumento nas doses de escória proporcionou aumentos significativos nos valores de $\mathrm{pH}, \mathrm{Ca}, \mathrm{Mg}$ e $\mathrm{Si}$ e redução na acidez potencial $\left(\mathrm{H}^{+}+\mathrm{Al}^{3+}\right)$.
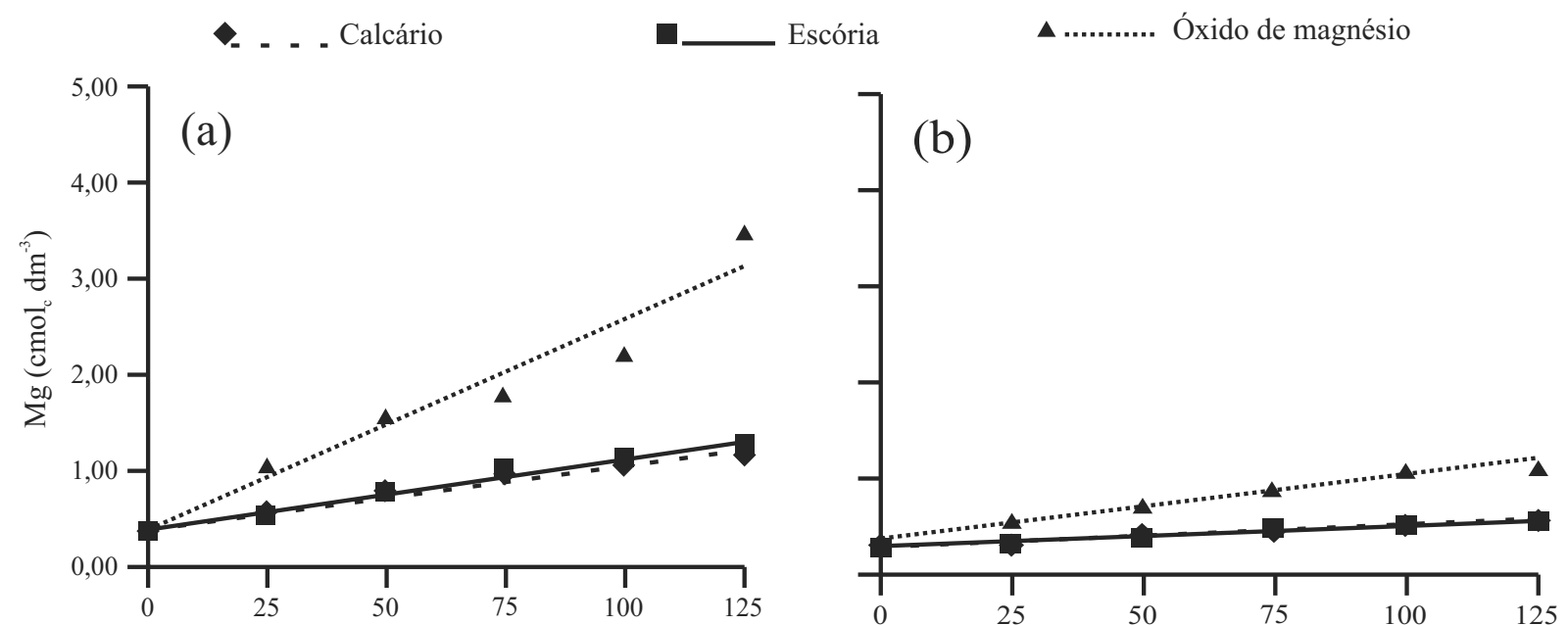

Doses $(\mathrm{NC} \%)$

$$
\begin{array}{rr}
-.-\hat{Y}=0,447+0,006 x & R^{2}=0,96 \\
-\hat{Y}=0,393+0,007 x & R^{2}=0,99 \\
\cdots \cdots . . . . . \hat{Y}=0,409+0,022 x & R^{2}=0,94
\end{array}
$$

$$
\begin{array}{rr}
--\quad \hat{Y}=0,306+0,002 x & R^{2}=0,98 \\
-\hat{Y}=0,311+0,002 x & R^{2}=0,96 \\
\cdots \cdots . . . . \hat{Y}=0,379+0,007 x & R^{2}=0,97
\end{array}
$$

Figura 5 - Valores médios de magnésio $\left(\mathrm{cmol}_{\mathrm{c}} \mathrm{dm}^{-3}\right)$ do solo para cada tipo de corretivo (calcário, escória e óxido de magnésio) em função das doses estudadas $(0 ; 25 ; 50 ; 75 ; 100$ e 125\% da necessidade de corretivo) para o LVAarg (a) e o LVAmed (b) 


\section{Conclusões}

1. As aplicações de doses crescentes de escória e óxido de magnésio até o limite estudado neste trabalho favoreceram um decréscimo da acidez do solo;

2. O óxido de magnésio demonstrou maior potencial como corretivo de acidez de solo e como fonte de magnésio para o solo.

\section{Agradecimentos}

Ao Centro de Ciências Agrárias da Universidade Federal do Espírito Santo pelo apoio técnico científico.

À Empresa Brasileira de Pesquisa Agropecuária (EMBRAPA) pela disponibilização dos laboratórios de análises de solos.

Ao Centro de Tecnologia Mineral (CETEM) e ao Conselho Nacional de Desenvolvimento Científico e Tecnológico (CNPq) pela concessão da bolsa ao primeiro autor.

À Magnesita S.A. pelo fornecimento do óxido de magnésio utilizado neste estudo.

\section{Referências}

BARBOSA FILHO, M. P. et al. Silicato de cálcio como fonte de silício para o arroz de sequeiro. Revista Brasileira de Ciência do Solo, v. 25, n. 02, p. 325-330, 2001

CARVALHO-PUPATTO, J. G. et al. Efeito de escória de alto forno no crescimento radicular e na produtividade de arroz. Pesquisa Agropecuária Brasileira, v. 38, n. 11, p. 1323-1328, 2003.

CHAVES, L. H. G. et al. Variabilidade de propriedades químicas de um Neossolo Flúvico da Ilha de Picos (Pernambuco). Revista Ciência Agronômica, v. 37, n. 02, p. 135-141, 2006.

COMPANHIA NACIONAL DE ABASTECIMENTO (CONAB). Estimativa da safra brasileira de café 2009/2010. Brasília, 2009. Disponível em: <http://www.conab.gov.br>. Acesso em: 12 mai. 2010.

EMPRESABRASILEIRADEPESQUISAAGROPECUÁRIA (EMBRAPA). Manual de métodos de análises de solo. 2. ed. Rio de Janeiro: Ministério da Agricultura e do Abastecimento, 1997. 212 p.

EMPRESA BRASILEIRA DE PESQUISA AGROPECUÁRIA. Sistema Brasileiro de Classificação de Solos. 2. ed. Rio de Janeiro: EMBRAPA Solos, 2006. 306p.

FORTES, C. A. et al. Níveis de silicato de cálcio e magnésio na produção das gramíneas marandu e tanzânia cultivadas em um neossolo quartzarênico. Revista Ciência e Agrotecnologia, v. 32 , n. 01 , p. $267-274,2008$.
FERREIRA, D. F. Análises estatísticas por meio do Sisvar para Windows 4.0. In: REUNIÃO ANUAL DA REGIÃO BRASILEIRA DA SOCIEDADE INTERNACIONAL DE BIOMETRIA, 45., 2000, São Carlos. Anais... São Carlos: UFSCAR, 2000. p. 255-258.

FREIRE, J. C et al. Resposta do milho cultivado em casa de vegetação a níveis de água em solos da região de Lavras-MG. Revista Brasileira de Ciência do Solo, v. 04, n. 01, p. 5-8, 1980.

MESQUITA, L. F. et al. Escória de siderurgia e óxido de magnésio como corretivos da acidez em latossolos. In: ENCONTRO LATINO AMERICANO DE INICIAÇÃO CIENTÍFICA, 12.; ENCONTRO LATINO AMERICANO DE PÓS-GRADUAÇÃO, 8., 2008, São Bernardo do Campo. Anais... São Bernardo do Campo: UNIVAP, 2008.

MORELLI, M. Apostila didática da disciplina de morfologia e gênese do solo. Santa Maria: UFSM, 1986. 27 p.

MORELI, A. P. Café: histórico, variedades e mercados. Disponível em: $<$ http://www.agais.com/tpc/capitulo_1_aldemar. pdf $>$. Acesso em: 05 dez. 2010.

MALAVOLTA, E. Reação do solo e crescimento das plantas. In: SEMINÁRIO SOBRE CORRETIVOS AGRÍCOLAS, 1984, Piracicaba. Anais... Piracicaba: Cargill, 1984. p. 03-57.

NOLLA, A.; ANGHINONI, I. Métodos utilizados para a correção da acidez do solo no Brasil. Revista Ciências Exatas e Naturais, v. 06, n. 01, p. 97-111, 2004.

OLIVEIRA, C. M. R. et al. Corretivos da acidez do solo e níveis de umidade no desenvolvimento da cana-de-açúcar. Revista Brasileira de Ciências Agrárias, v. 05, n. 01, p. 25-31, 2010.

PAPAROTTE, I.; MACIEL, C. A. C. Efeitos do resíduo de gesso da indústria cerâmica sobre as propriedades químicas do solo. Engenharia Ambiental, v. 03, n. 01, p. 32-41, 2006.

PRADO, R. M.; FERNANDES, F. M. Eficiência da escória de siderurgia em areia quartzosa na nutrição e na produção de matéria seca de cana-de-açúcar. STAB, v. 18, n. 04, 2000a.

PRADO, R. M.; FERNANDES, F. M. Escória de siderurgia e calcário na correção da acidez do solo cultivado com cana-de-açúcar em vaso. Scientia Agrícola, v. 57, n. 04, p. 739-744, 2000 b.

PRADO, R. M.; FERNANDES, F. M. Resposta da cana-deaçúcar à aplicação da escória de siderurgia como corretivo de acidez do solo. Revista Brasileira de Ciência do Solo, v. 25, n. 01, p. 201-209, 2001.

PRADO, R. M.; NATALE, W. Efeitos da aplicação da escória de siderurgia ferrocromo no solo, no estado nutricional e na produção de matéria seca de mudas de maracujazeiro. Revista Brasileira de Fruticultura, v. 26, n. 01, p. 140-144, 2004.

PREZOTTI, L. C. et al. Manual de recomendação de calagem e adubação para o estado do Espírito Santo: $5^{\mathrm{a}}$ aproximação. Vitória, ES: SEEA; INCAPER; CEDAGRO, 2007. 305 p.

SOUSA, D. M. G.; MIRANDA, L. N.; OLIVEIRA, S.A. Acidez do solo e sua correção. In: NOVAIS, R. F.; ALVAREZ VENEGAS, V. H.; BARROS, N. F. et al. (Ed.). Fertilidade do solo. Viçosa, MG: SBCS, 2007. p. 205-274. 
STOCCO, F. C. et al. Uso de escórias de siderurgia na produção de matéria seca e perfilhamento de duas gramíneas do gênero Brachiaria em um Latossolo Vermelho-Amarelo. Bioscience Journal, v. 26, n. 02, p. 240-248, 2010.
VECCHI, R. E. Efeito do gesso e de diferentes corretivos de acidez em características químicas do solo, produção e estudo nutricional dos citros. 1993. 53 f. Monografia (Graduação em Agronomia) - Universidade Estadual Paulista, Jaboticabal, 1993. 